\section{HOT OFF THE PRESS WITH PRIZES}

Visit stand E08 at this year's BDTA Dental Showcase and meet the Dental Sky team

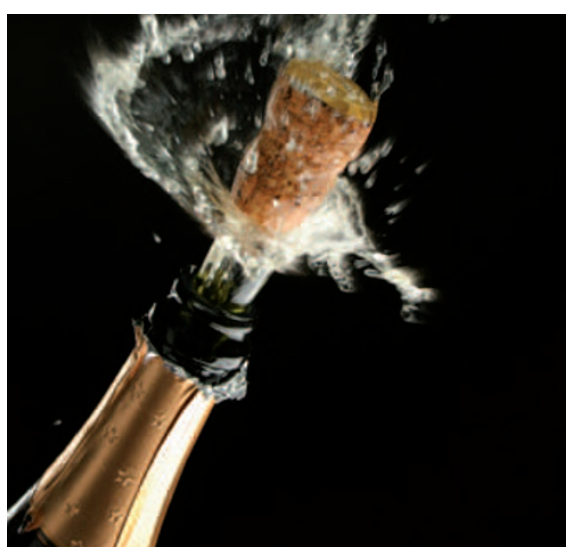

over a coffee and a cupcake. They have so much to offer with the launch of their new 2012 dental catalogue, the 'hot off the press' 2011 workwear catalogue, including new ranges from Cherokee, and their 48 page bumper monthly brochure packed with all the great offers you will have come to expect from Dental Sky over the last 12 years.

Place an order at the stand and you can claim either your free bottle of Champagne, a Canon Powershot camera, an Advent Vega Tablet or a Sony Bravia Smart TV!

Reach for the Sky! Reader response number 70

allows you to create beautifully invisible restorations with one shade. This micro hybrid composite material incorporates a new shade concept including an age related choice of enamel colours. Three inside shades are available for more complex shading.

Incorporating the best of industrial monomer innovation from DuPont, Kalore features an exclusive low shrinkage technology. On a microscopic level, this means that during and after polymerisation, adhesion between the fillers and the resin matrix is maintained.

GC will also be showing Initial IQ Layering Over Zirconia and Light Reflective Liners - the latest addition to the Initial IQ range.

Reader response number 71

\title{
SUPPORTING YOU IN YOUR DAILY PRACTICE LIFE
}

A warm welcome awaits dentists and DCPs visiting the Johnson \& Johnson display stand V13 at the Dental Showcase exhibition in Birmingham.

This is a very good opportunity for the whole dental team to learn more about Listerine, the role of mouthwash in oral hygiene and to try the latest addition to the Listerine range, Listerine Total Care Zero, at the rinsing booth on the stand.

Listerine Total Care Zero is formulated to meet the individual needs and preferences of patients who may prefer a mouthwash which is alcoholfree and has a less intense taste.

This year, for the first time, the Listerine Team will be joined on the stand by their colleagues from ETHICON, a division of Johnson \& Johnson Medical Limited, who will showcase their wound closure products, including a unique range of absorbable antibacterial sutures.

Johnson \& Johnson look forward to showing you how they can support you in your daily practice life.

Reader response number 72 